\title{
Reaction Mechanism and Kinetic Analysis of the Solid-State Reaction to Synthesize Single-Phase $\mathrm{Li}_{2} \mathrm{Co}_{2} \mathrm{O}_{4}$ Spinel
}

\section{Kingo Ariyoshi, Kazuki Yuzawa, Yusuke Yamada}

\begin{tabular}{|c|l|}
\hline Citation & The Journal of Physical Chemistry C. 124(15); 8170-8177 \\
\hline Issue Date & 2020-03-22 \\
\hline Type & Journal Article \\
\hline Textversion & Author \\
\hline Rights & $\begin{array}{l}\text { This document is the Accepted Manuscript version of a Published Work that appeared } \\
\text { in final form in the Journal of Physical Chemistry C., copyright } @ \text { American Chemical } \\
\text { Society after peer review and technical editing by the publisher. } \\
\text { To access the final edited and published work see } \\
\text { https://doi.org/10.1021/acs.jpcc.0c01115. }\end{array}$ \\
\hline $\begin{array}{c}\text { Supporting } \\
\text { Information }\end{array}$ & $\begin{array}{l}\text { The Supporting Information is available free of charge at } \\
\text { https://pubs.acs.org/doi/10.1021/acs.jpcc.0c01115. } \\
\text { TG analysis and additional characterization of the prepared materials (PDF) }\end{array}$ \\
\hline DOI & \begin{tabular}{l}
$10.1021 / a c s . j p c c .0 c 01115$ \\
\hline
\end{tabular}
\end{tabular}

\section{Self-Archiving by Author(s)}

Placed on: Osaka City University Repository

Ariyoshi, K., Yuzawa, K., \& Yamada, Y. (2020). Reaction Mechanism and Kinetic Analysis of the Solid-State Reaction to Synthesize Single-Phase Li2Co2O4 Spinel. The Journal of Physical Chemistry C, 124(15), 8170-8177. https://doi.org/10.1021/acs.jpcc.0c01115 


\section{Reaction Mechanism and Kinetic Analysis of the}

Solid-State Reaction to Synthesize Single-Phase

\section{$\mathrm{Li}_{2} \mathrm{Co}_{2} \mathrm{O}_{4}$ Spinel}

Kingo Ariyoshi*, Kazuki Yuzawa, and Yusuke Yamada*

Department of Applied Chemistry and Bioengineering, Graduate School of Engineering, Osaka

City University, 3-3-138 Sugimoto, Sumiyoshi-ku, Osaka 558-8585, Japan 
ABSTRACT Lithium cobalt oxide has two polymorphs that display different electrochemical properties despite their identical redox reactions: a high-temperature phase having a layered structure $\left(\mathrm{LiCoO}_{2} ; \mathrm{HT}-\mathrm{LCO}\right)$ and a low-temperature phase with a spinel-framework $\left(\mathrm{Li}_{2} \mathrm{Co}_{2} \mathrm{O}_{4}\right.$; LT-LCO). The synthetic conditions of the single-phase LT-LCO were determined by thermogravimetric (TG) analysis performed on the solid-state reaction of $\mathrm{Li}_{2} \mathrm{CO}_{3}$ and $\mathrm{Co}_{3} \mathrm{O}_{4}$. The results revealed that LCO synthesis was a second order reaction with the activation energy of $E_{\mathrm{a}}=150 \mathrm{~kJ} \mathrm{~mol}^{-1}$ and preexponential factor of $A=9.2 \times 10^{7} \mathrm{~s}^{-1}$. XRD studies indicated that low temperature synthesis below $350{ }^{\circ} \mathrm{C}$ is necessary to obtain the single-phase LT phase, because the HT-phase fraction increased with increasing synthesis temperature. Virtually single-phase LT-LCO obtained by calcining at $325^{\circ} \mathrm{C}$ for $240 \mathrm{~h}$ exhibited zero-strain lithium insertion. These results contribute towards the establishment of a synthetic method for novel materials with reduced spinel structure. 


\section{INTRODUCTION}

Since the commercialization of lithium-ion batteries in the early 1990s, a wide variety of lithium insertion materials in which lithium ions can be reversibly inserted into or extracted from a solid matrix have been discovered. ${ }^{1-4}$ These include lithium transition metal oxides with layered, spinel, and forsterite structures. ${ }^{5-11}$ Among the lithium insertion materials reported to date, lithium cobalt oxide $\left(\mathrm{LiCoO}_{2} ; \mathrm{LCO}\right)$ comprising a layered structure has been frequently used as a positive electrode material owing to its high operating voltage, large gravimetric/volumetric capacity, and excellent cycleability. ${ }^{12-14}$ LCO has two polymorphs depending on the synthetic temperature: a layered structure for the high-temperature phase $\left(\mathrm{LiCoO}_{2} ;\right.$ HT-LCO) and a spinel-framework structure for the low-temperature phase $\left(\mathrm{Li}_{2} \mathrm{Co}_{2} \mathrm{O}_{4}\right.$; LT-LCO). ${ }^{12-22}$ LT-LCO has the same chemical formula as that of the HT phase but with a different cationic arrangement. Thus, in LT-LCO, the Co and oxide ions form a spinelframework in which the Li ions fully occupy the vacant octahedral sites to form a reduced (or lithiated) spinel structure. ${ }^{14-19}$ The LT-LCO was extensively studied from the late 1990s to the early 2000s, because the LT-LCO having 3D-framework would have superior dimensional stability to HT-phase. However, the electrochemical performance of the LT-LCO could not surpass that of the HT-LCO, owing to difficulties in the synthesis of single-phase LT-LCO.

Recently, the substitution of Co with a small amount of a different element, particularly Ni, has led to the creation of a material that approaches the single phase. ${ }^{18,19}$ In our previous paper, ${ }^{19}$ we reported that Ni-substituted LCO with a reduced spinel structure is a zero-strain insertion material that does not exhibit any lattice dimension changes during charge and discharge. Zero-strain materials should exhibit excellent cycleability because of the absence of internal stress leading to particle fracture during cycling, as proved by lithium titanium oxide $\left(\mathrm{Li}\left[\mathrm{Li}_{1 / 3} \mathrm{Ti}_{5 / 3}\right] \mathrm{O}_{4}\right.$; LTO). ${ }^{23,24}$ Therefore, zero-strain lithium-ion batteries can be designed by 
combining the zero-strain LT-LCO material with LTO, which is ideally one of the most suitable battery materials for long-life applications.

Zero-strain LT-LCO is an attractive positive electrode material, however, a single LT phase is hard to obtain without Ni-substitution, owing to contamination with the HT phase even at low calcination temperatures $\left(\sim 450{ }^{\circ} \mathrm{C}\right)$. Therefore, in this study, the kinetics of the LT-LCO synthetic process was elucidated by isothermal and non-isothermal thermogravimetric (TG) analysis to determine a reaction model and its kinetic parameters. Such data provides further insight into single-phase LT-LCO formation.

The single-phase LT-LCO thus synthesized is expected to exhibit a smaller change in its lattice dimension than that of the Ni-substituted LCO based on the relationship between the change in the lattice parameters and amount of Co ions. ${ }^{25}$ Also, the single-phase LT-LCO allows exact comparison of the electrochemical properties of LT- and HT-LCO. The differences and similarities of the two polymorphs would indicate the structural factors affecting their electrochemical properties, because the charge-discharge curves of the HT and LT phases are significantly different. Thus, the LT phase has a lower electrode potential than the HT phase and presents flat charge-discharge curves in contrast to the sloping voltage profiles presented by the HT phase. ${ }^{14,18,19}$

\section{EXPERIMENTAL}

Synthesis and Structural Characterization of $\mathrm{Li}_{2} \mathrm{Co}_{2} \mathrm{O}_{4}$. The $\mathrm{Li}_{2} \mathrm{Co}_{2} \mathrm{O}_{4}$ samples were prepared by a solid-state synthetic method. A reaction mixture of $\mathrm{Li}_{2} \mathrm{CO}_{3}$ (Wako Chem. Ind. Ltd., Japan) and $\mathrm{Co}_{3} \mathrm{O}_{4}$, obtained by calcining basic cobalt carbonate (Wako Chem. Ind. Ltd., Japan) at $500{ }^{\circ} \mathrm{C}$ for $16 \mathrm{~h}$, was heated to several temperatures and times under air in an electric muffle furnace (Advantec Toyo Kaisha, Ltd., Japan). The synthesized materials were characterized by powder X-ray diffraction (XRD) using an X-ray diffractometer (XRD-6100, 
Shimadzu Corp., Japan) equipped with a graphite monochromator, using FeK $\alpha$ radiation $(\lambda=$ $1.9373 \AA$ ), operated at $40 \mathrm{kV}$ and $15 \mathrm{~mA}$. The data were collected in the $2 \theta$ range of $10-100^{\circ}$ at the scan rate of $0.5^{\circ} \mathrm{min}^{-1}$.

The fractions of the LT- and HT-LCO phases were estimated by peak deconvolution of the strong diffraction lines at $24^{\circ}$ in $2 \theta$ into the 111 line for the cubic LT phase and 003 line for the hexagonal HT phase. A pseudo-Voigt function combined with Lorentz and Gaussian functions was generally used for the peak fitting of the diffraction lines. ${ }^{26}$ When fitting the diffraction line using the pseudo-Voigt function, the proportion of the Gaussian component was extremely high, while that of the Lorentz component was sufficiently low to be neglected. Therefore, peak deconvolution was performed using the Gaussian function (eq 1) instead of the pseudo-Voigt function.

$y=y_{0}+\frac{A}{\sqrt{2 \pi} \times w} \exp \left(\frac{-\left(x-x_{C}\right)^{2}}{2 w^{2}}\right)$

where $y_{0}$ represents the background intensity, $w$ represents the full width at half maximum, $A$ represents the height of the peak, and $x_{\mathrm{c}}$ represents the position of the peak center.

TG Analysis. Isothermal and non-isothermal TG analysis was performed using a TG analyzer (TGA-60 Plus, Shimadzu Corp., Japan). Stoichiometric $\mathrm{Li}_{2} \mathrm{CO}_{3}$ and $\mathrm{Co}_{3} \mathrm{O}_{4}$ (molar ratio, 3:2) were mixed in a mortar, and the mixture $(\sim 20 \mathrm{mg})$ was placed into a platinum dish. For nonisothermal TG analysis, the samples were heated at a constant rate from room temperature to $1000{ }^{\circ} \mathrm{C}$ under air atmosphere. For isothermal TG analysis, the samples were heated at the constant temperatures 410,430 , and $450{ }^{\circ} \mathrm{C}$ for $1.5,3$, and $6 \mathrm{~h}$, respectively.

Electrochemical Measurements. The structure of the electrochemical cell used for material 
testing has been previously reported. ${ }^{27}$ To prepare the positive electrode, a black viscous slurry comprising $88 \mathrm{wt} \% \mathrm{Li}_{2} \mathrm{Co}_{2} \mathrm{O}_{4}, 6 \mathrm{wt} \%$ acetylene black, and $6 \mathrm{wt} \%$ polyvinylidene fluoride dispersed in $N$-methyl-2-pyrrolidone was cast onto aluminum foil. $N$-methyl-2-pyrrolidone was evaporated at $80^{\circ} \mathrm{C}$ for $1 \mathrm{~h}$ under vacuum and the electrode was dried under vacuum at $150{ }^{\circ} \mathrm{C}$ overnight. Finally, the electrode was punched out to form a disk (diameter, $16.0 \mathrm{~mm}$ ). The loading weight of the electrodes were approximately $15 \mathrm{mg} \mathrm{cm}^{-2}$. The Li metal electrode was used as the negative electrode. The electrolyte comprised $1 \mathrm{M} \mathrm{LiPF}_{6}$ dissolved in 3:7 (v/v) ethylene carbonate/dimethyl carbonate solution (Kishida Chemical Co., Ltd., Osaka, Japan). Two sheets of porous membrane (Celgard 2320) were used as the separator. To investigate the electrochemical properties of the $\mathrm{Li}_{2} \mathrm{Co}_{2} \mathrm{O}_{4}$ samples, charge-discharge cycles of the cells were performed in the voltage range $2.5-4.2 \mathrm{~V}$ at the rate $0.25 \mathrm{~mA} \mathrm{~cm}^{-2}$ and a temperature of $25^{\circ} \mathrm{C}$ using a battery cycler (HJ-106SM6, Hokuto Denko Corp., Japan).

\section{RESULTS AND DISCUSSION}

Investigation of the Reaction Kinetics of $\mathrm{Li}_{2} \mathrm{Co}_{2} \mathrm{O}_{4}$ Formation by TG Analysis. Kinetics of the solid-state reaction of $\mathrm{Li}_{2} \mathrm{CO}_{3}$ and $\mathrm{Co}_{3} \mathrm{O}_{4}$ was investigated by $\mathrm{TG}$ analysis carried out under non-isothermal conditions; i.e., heating the mixture of $\mathrm{Li}_{2} \mathrm{CO}_{3}$ and $\mathrm{Co}_{3} \mathrm{O}_{4}$ at the rate $2-40{ }^{\circ} \mathrm{C}$ $\min ^{-1}$ (Figure 1). The TG curves displayed the following trend: the sample weight began to decrease at the temperature range $350-400{ }^{\circ} \mathrm{C}$ and continued to decrease until the temperature reached $\sim 600{ }^{\circ} \mathrm{C}$; the weight-loss rate reached its maximum at $430-530{ }^{\circ} \mathrm{C}$. Subsequently, a small amount of weight loss was observed again in the range $700-800{ }^{\circ} \mathrm{C}$. For all the measurements, the weight loss at $1000{ }^{\circ} \mathrm{C}$ was in the range $16.8-17.2 \%$. The observed value agreed well with the calculated values, assuming the formation of $\mathrm{Li}_{2} \mathrm{Co}_{2} \mathrm{O}_{4}$ from $\mathrm{Li}_{2} \mathrm{CO}_{3}$ and $\mathrm{Co}_{3} \mathrm{O}_{4}(16.5 \%)$. These results indicated that the LCO synthesis progressed according to the chemical equation: 
$3 \mathrm{Li}_{2} \mathrm{CO}_{3}+2 \mathrm{Co}_{3} \mathrm{O}_{4}+1 / 2 \mathrm{O}_{2} \rightarrow 3 \mathrm{Li}_{2} \mathrm{Co}_{2} \mathrm{O}_{4}+3 \mathrm{CO}_{2}$

The activation energy of the reaction was calculated from the equation proposed by Ozawa (Ozawa equation) based on the TG curves. According to the Ozawa equation: ${ }^{28}$

$$
\log \beta=-0.4576 \frac{E_{\mathrm{a}}}{R T}
$$

where, $\beta, E_{\mathrm{a}}, R$, and $T$ are the heating rate, activation energy, gas constant, and absolute temperature, respectively. On the basis of the Ozawa equation, there should be a linear relationship between the logarithm of the heating rate and the reciprocal of the absolute temperature at different extents of the reaction, $\alpha$. Figure 2a illustrates an Ozawa plot (horizontal axis, $1 / T$ and vertical axis, $\log \beta$ ) to estimate the activation energy from the slope of the lines at each $\alpha$ value. A good linear relationship was obtained for each line in the figure. These lines were virtually parallel in the $\alpha$ range of $0.2-0.8$. Figure $2 \mathrm{~b}$ displays the activation energy derived from the slope of the lines. The activation energy was constant, at $150 \mathrm{~kJ} \mathrm{~mol}^{-1}$, in the range $0.3 \leq \alpha \leq 0.8$. To confirm the reliability of the activation energy calculated from the Ozawa equation, the activation energy of the reaction was also calculated using the Kissinger equation (Figure S1). ${ }^{29}$ The calculated value $\left(152.3 \pm 7.1 \mathrm{~kJ} \mathrm{~mol}^{-1}\right)$ was well in agreement with that obtained from the Ozawa equation. 


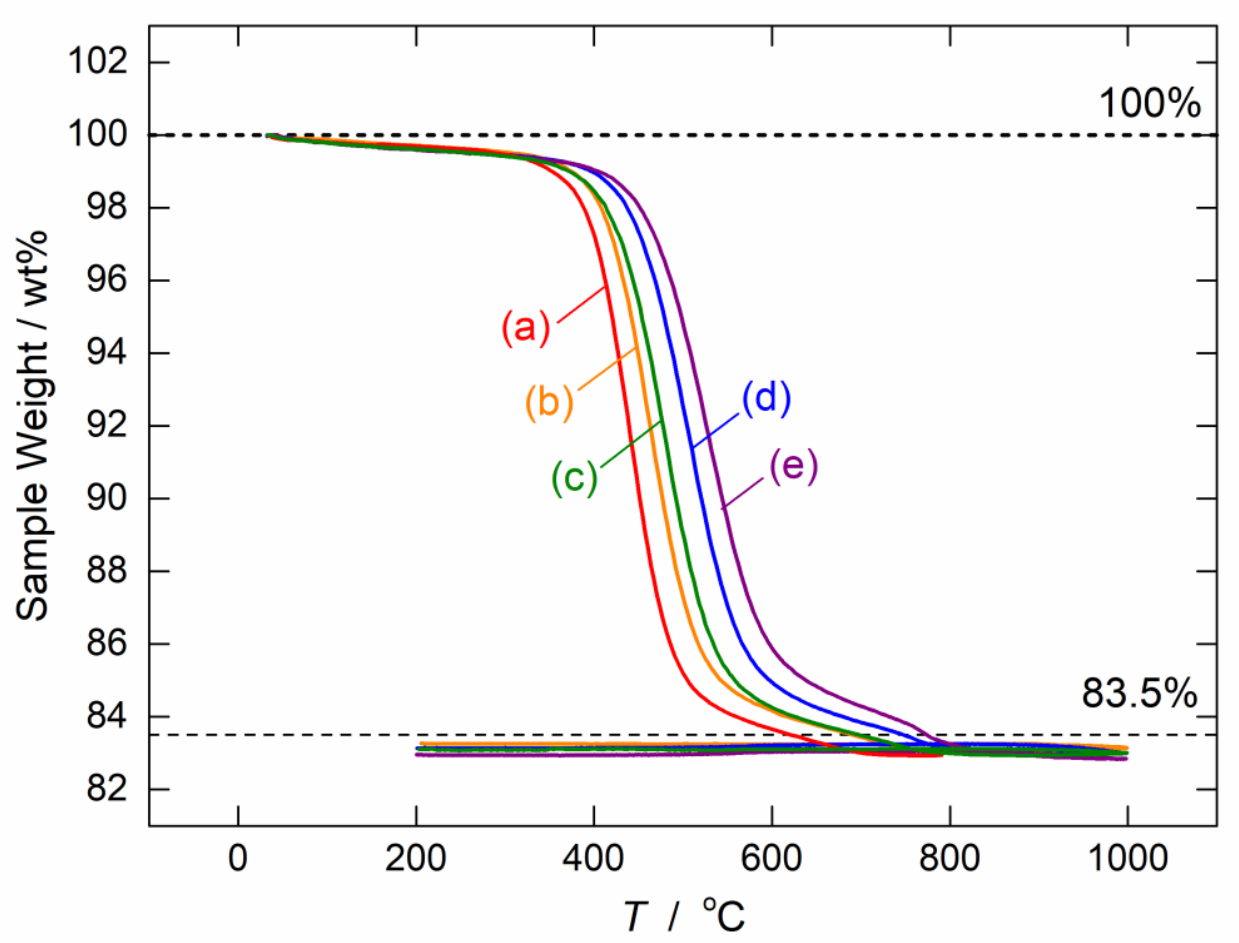

Figure 1. Non-isothermal thermogravimetric curves for the reaction between $\mathrm{Li}_{2} \mathrm{CO}_{3}$ and $\mathrm{Co}_{3} \mathrm{O}_{4}$ in air at the heating rates: (a) 2 , (b) 5 , (c) 10 , (d) 20 , and (e) $50{ }^{\circ} \mathrm{C} \mathrm{min}^{-1}$.

TG analysis under isothermal conditions was next carried out to determine the reaction model in the solid-state reaction (Figure S2). The reaction temperature was set to 410, 430, and $450{ }^{\circ} \mathrm{C}$. The samples were heated to each temperature at the heating rate $50{ }^{\circ} \mathrm{C} \mathrm{min}-1$ and maintained for a sufficient time after reaching the set temperature. Finally, the temperature was raised again to $1000{ }^{\circ} \mathrm{C}$, whereby the reaction proceeded to completion. The initial weight was corresponding to $\alpha=0$ before the reaction was initiated, while the final weight at $1000{ }^{\circ} \mathrm{C}$ was corresponding to $\alpha=1$ when the reaction was complete. The value of $\alpha$ was calculated from the following equation.

$\alpha=\frac{w(R T)-w(t)}{w(R T)-w\left(1000^{\circ} \mathrm{C}\right)}$ 
where $w(\mathrm{RT}), w\left(1000^{\circ} \mathrm{C}\right)$, and $w(t)$ are the sample weights at room temperature, $1000{ }^{\circ} \mathrm{C}$, and during TG measurements, respectively.
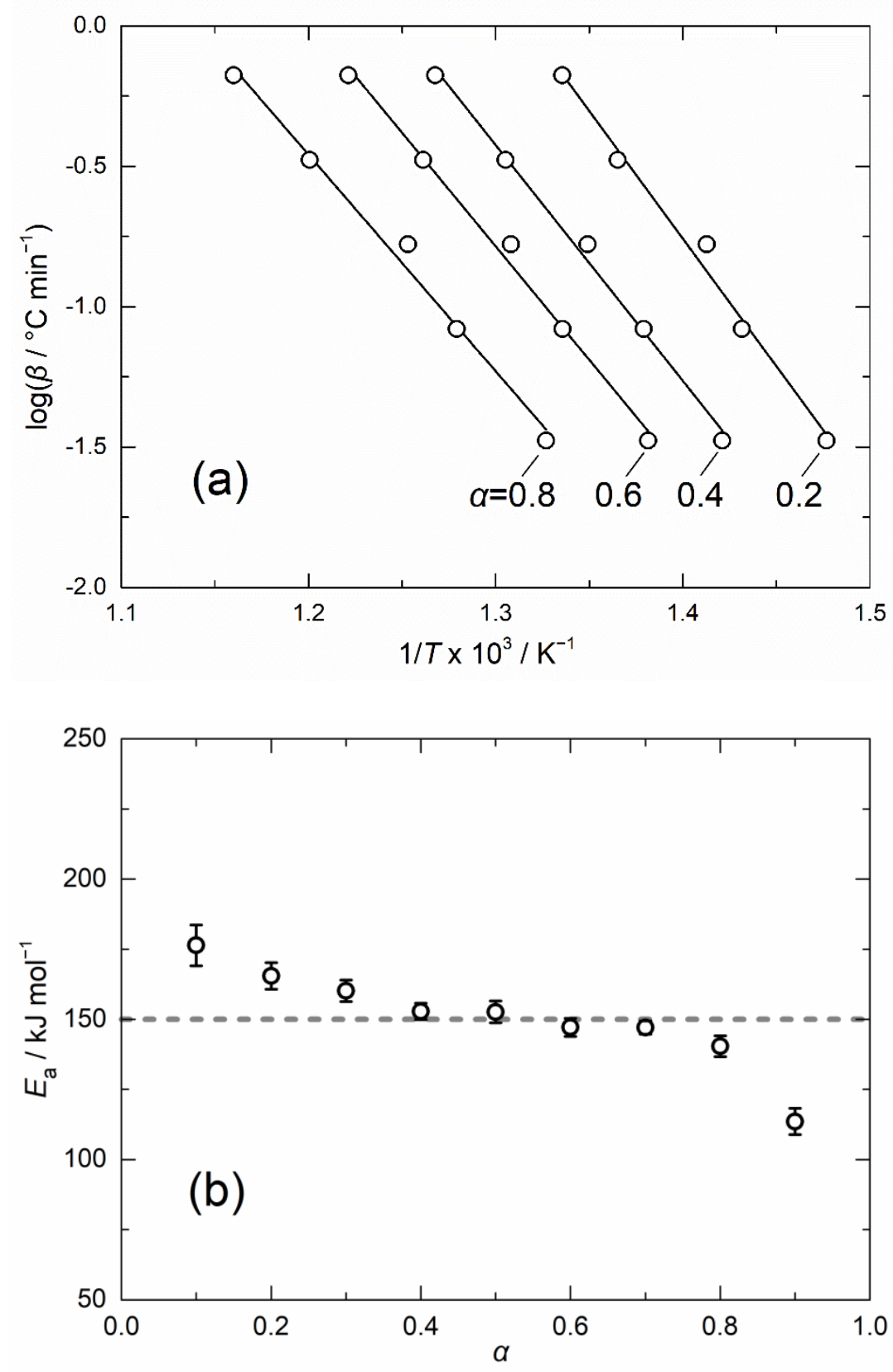

Figure 2. (a) Plots of the logarithm of the heating rate $(\log \beta)$ versus the reciprocal of the absolute temperature $(1 / T)$ for the reaction between $\mathrm{Li}_{2} \mathrm{CO}_{3}$ and $\mathrm{Co}_{3} \mathrm{O}_{4}$ in air at the different extents of the reaction $\alpha=0.8,0.6,0.4$, and 0.2. (b) Activation energy $\left(E_{a}\right)$ for the different $\alpha$ values calculated from the plots of $\log \beta$ versus $1 / T$. 


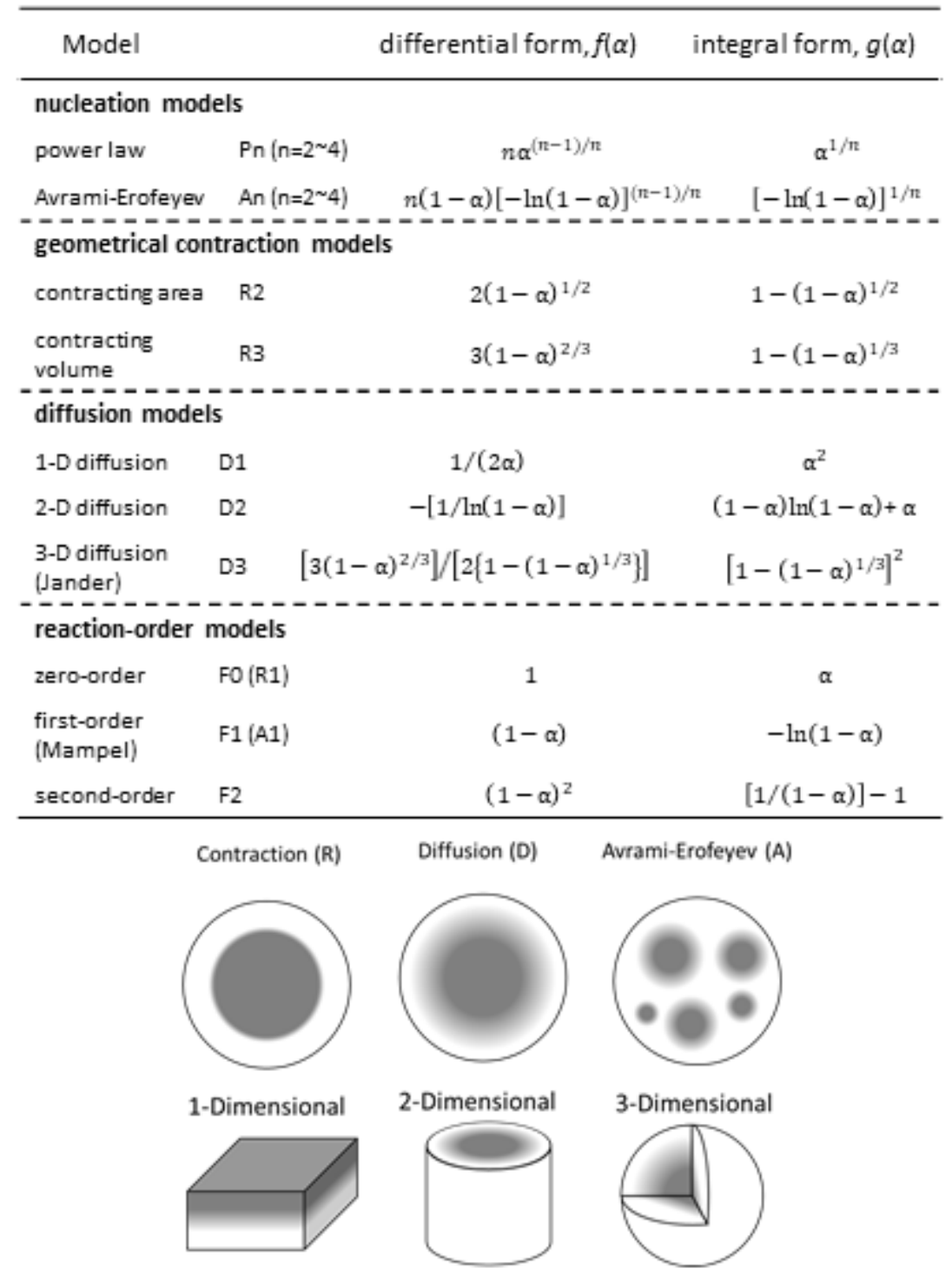

Figure 3. Reaction models for the solid-state reactions and the differential and integral forms of the rate equations.

The kinetic equation of the solid-state reaction can be expressed by the equation: ${ }^{30,31}$

$$
g(\alpha)=k t
$$

where $k$ is the rate constant, $g(\alpha)$ is a function representing the integral reaction model, and $t$ is the time. The reaction model depends on the reaction mechanism and can be expressed as a function that includes the extent of the reaction. ${ }^{30,31}$ Therefore, when $t$ was plotted against various $g(\alpha)$ values, the reaction model $g(\alpha)$ was determined from the linear relationship of the 
plot. By applying the various reaction models (Figure 3) for curve fitting, a linear relationship was obtained by assuming a secondary reaction model (Figure 4a) in which:

$$
k t=\frac{\alpha}{1-\alpha}
$$

The rate constant $k$ can be expressed by the Arrhenius equation:

$$
k=A \exp \left(\frac{-E_{a}}{R T}\right)
$$

Substitution of equations (6) and (7) into equation (5) gives the extents of the reaction $\alpha$ as a function of time $t$ and temperature $T$ :

$$
\frac{\alpha}{1-\alpha}=\operatorname{Atexp}\left(\frac{-E_{a}}{R T}\right)
$$

Because the slope of the straight line in Figure 4 a corresponds to the rate constant $k$, the Arrhenius parameter was obtained from the rate constant at each temperature from eq (6). Eq (7) was modified to the equation:

$$
\ln k=\ln A-\frac{E_{a}}{R T}
$$

Based on eq (9), a graph of $\ln k$ versus $1 / T$ (Figure $4 \mathrm{~b}$ ) was plotted to determine the activation energy (slope) and pre-exponential factor (intercept). Thus, the kinetic parameters $E_{\mathrm{a}}=150 \mathrm{~kJ}$ $\mathrm{mol}^{-1}$ and $A=9.2 \times 10^{7} \mathrm{~s}^{-1}$, with a standard error of $0.63 \mathrm{~kJ} \mathrm{~mol}^{-1}$ and $9.7 \times 10^{6} \mathrm{~s}^{-1}$, respectively, were determined. These results indicated that the solid-state reaction of $\mathrm{Li}_{2} \mathrm{Co}_{2} \mathrm{O}_{4}$ from $\mathrm{Li}_{2} \mathrm{CO}_{3}$ and $\mathrm{Co}_{3} \mathrm{O}_{4}$ obeys the kinetics based on the second-order reaction model. This differed from the diffusion-controlled reaction reported for similar reactions such as $\mathrm{LiNiO}_{2}$ from $\mathrm{LiNO}_{3}$ and $\mathrm{NiO}^{32,33}$ and $\mathrm{LiCoO}_{2}$ from $\mathrm{Li}_{2} \mathrm{CO}_{3}$ and $\mathrm{Co}_{3} \mathrm{O}_{4} \cdot{ }^{34}$ 
(a)

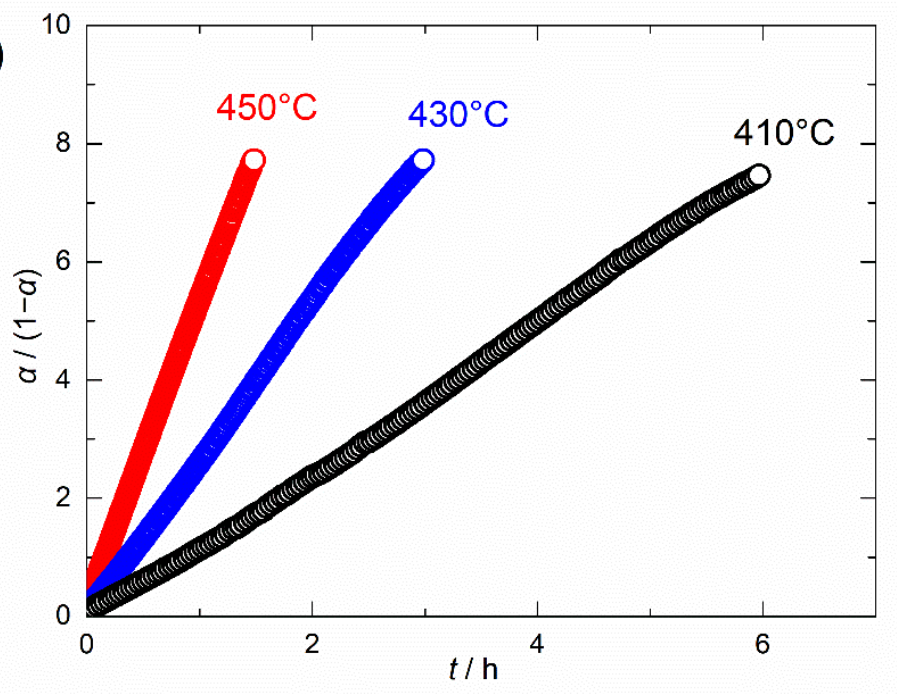

(b)

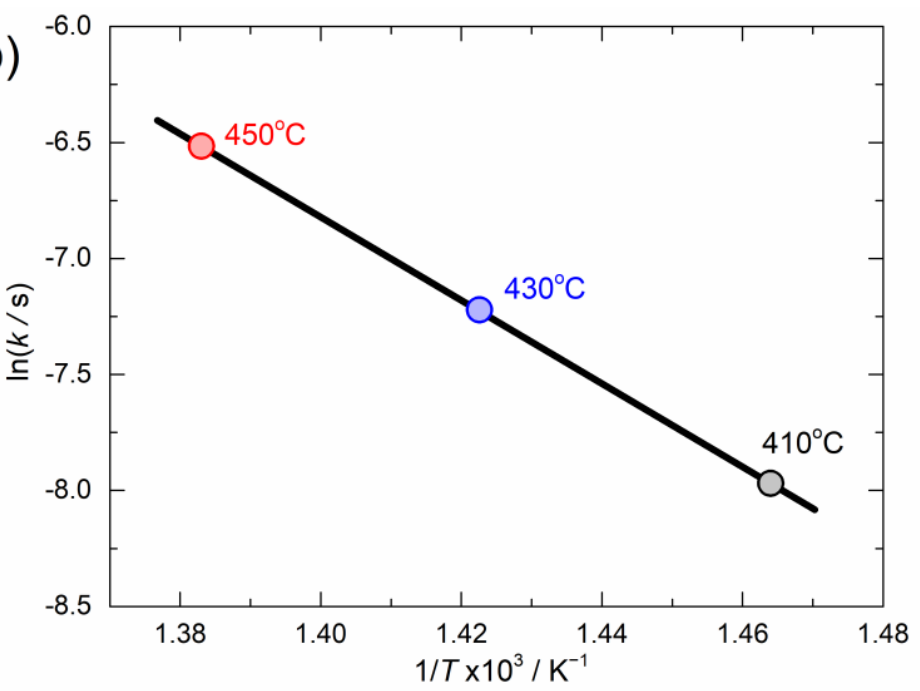

Figure 4. (a) $\alpha /(1-\alpha)$ versus time $(t)$ plots for the reaction between $\mathrm{Li}_{2} \mathrm{CO}_{3}$ and $\mathrm{Co}_{3} \mathrm{O}_{4}$ at the constant temperatures 450 (red), 430 (blue), and 410 (black) ${ }^{\circ} \mathrm{C}$. (b) Arrhenius plot of the logarithm of the reaction rate constant $(\ln k)$ versus the reciprocal of the absolute temperature $(1 / T)$.

Theoretical Response Rate Based on Kinetic Analysis. In the solid-state reaction of inorganic materials, the rate of a reaction is affected by several synthetic conditions including the sample type (weight and thickness), carrier gas, and sample pans. ${ }^{35}$ To verify whether the reaction rate determined from the TG analysis can be applied to the solid-state reaction of LCO in gram-scale synthesis, the LCO reaction was performed at $325{ }^{\circ} \mathrm{C}$ for $3-10 \mathrm{~d}$ and 
subsequently analyzed by XRD and TG analyses. Figure 5 presents the XRD patterns of the samples calcined at $325^{\circ} \mathrm{C}$ for 3,6 , and $10 \mathrm{~d}$. The XRD patterns of simulated $\mathrm{Li}_{2} \mathrm{CO}_{3}$ (Figure 5a) and LT-LCO (Figure 5e) are displayed for comparison. With an increase in the calcination time, the diffraction lines around $2 \theta=40^{\circ}$ belonging to the raw $\mathrm{Li}_{2} \mathrm{CO}_{3}$ decreased, indicating that $\alpha$ increases with increasing calcination time. The extent of the reaction of these samples was determined by TG analysis (Figure 6a). In the figure, a 3:2 $\mathrm{Li}_{2} \mathrm{CO}_{3}$ and $\mathrm{Co}_{3} \mathrm{O}_{4}$ mixture and the sample calcined at $450{ }^{\circ} \mathrm{C}$ for $16 \mathrm{~h}$ meet the criteria $\alpha=0$ and 1.0 , respectively. The values of $\alpha$ were estimated as $0.41,0.64$, and 0.78 for the calcination periods 3,6 , and $10 \mathrm{~d}$, respectively. When the values of $\alpha /(1-\alpha)$ were plotted against the calcination time (Figure $6 \mathrm{~b}$ ), a linear relation was obtained. This line was used to calculate the kinetic parameters, namely $E_{\mathrm{a}}=153 \mathrm{~kJ} \mathrm{~mol}^{-1}$ and $A=8.6 \times 10^{7} \mathrm{~s}^{-1}$. These values are consistent with those previously obtained by isothermal TG analysis, indicating that the $\alpha$ value of the actual solid-state reaction of $\mathrm{Li}_{2} \mathrm{Co}_{2} \mathrm{O}_{4}$ can be determined from the calcination temperature and time using these kinetics parameters. 

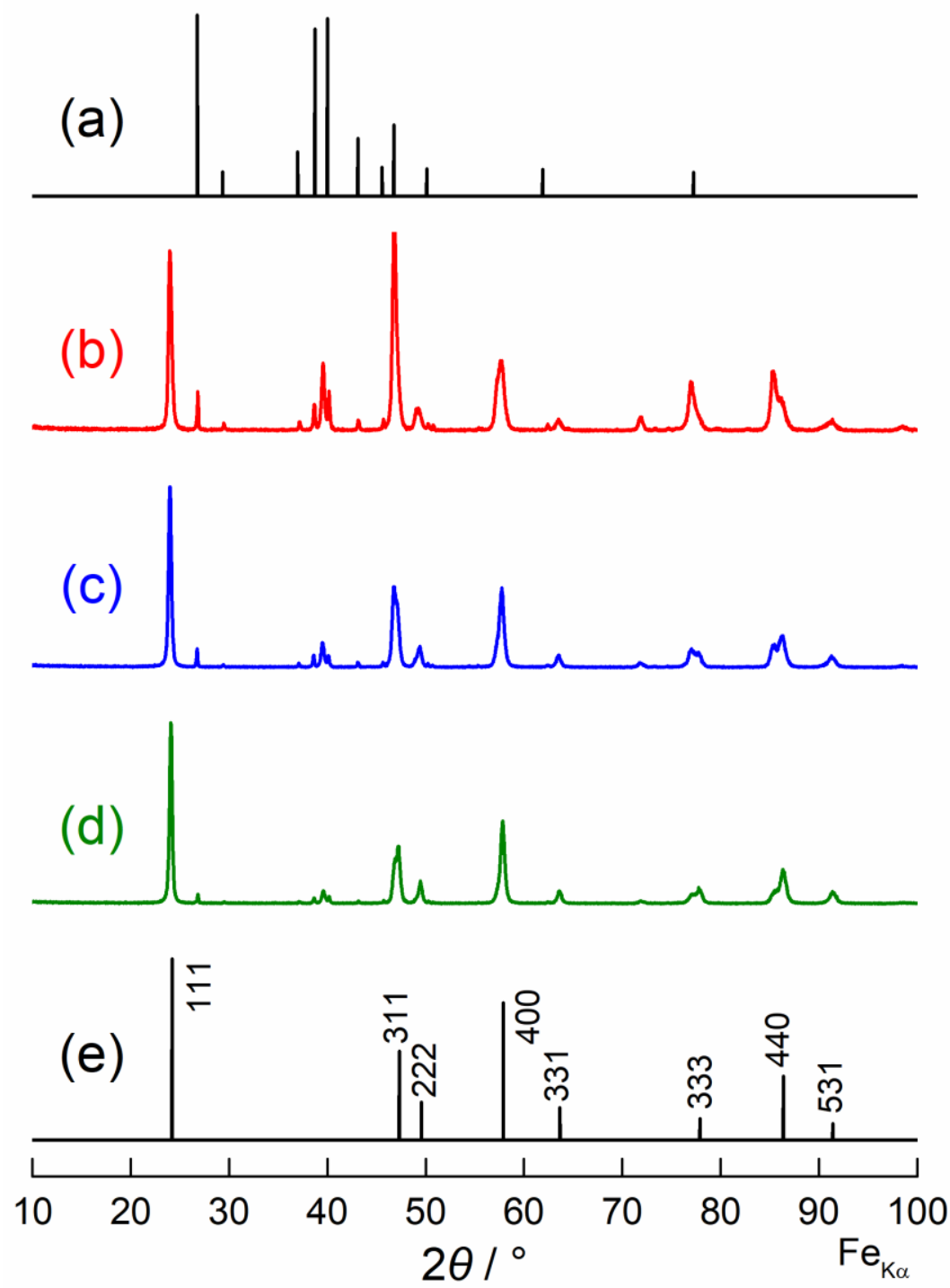

Figure 5. X-ray diffraction (XRD) patterns of the reaction products formed from $\mathrm{Li}_{2} \mathrm{CO}_{3}$ and $\mathrm{Co}_{3} \mathrm{O}_{4}$ calcined at $325^{\circ} \mathrm{C}$ for (b) 3, (c) 6, and (d) $10 \mathrm{~d}$. Simulated XRD patterns of (a) $\mathrm{Li}_{2} \mathrm{CO}_{3}$ and (e) LT-LCO are included for comparison. 

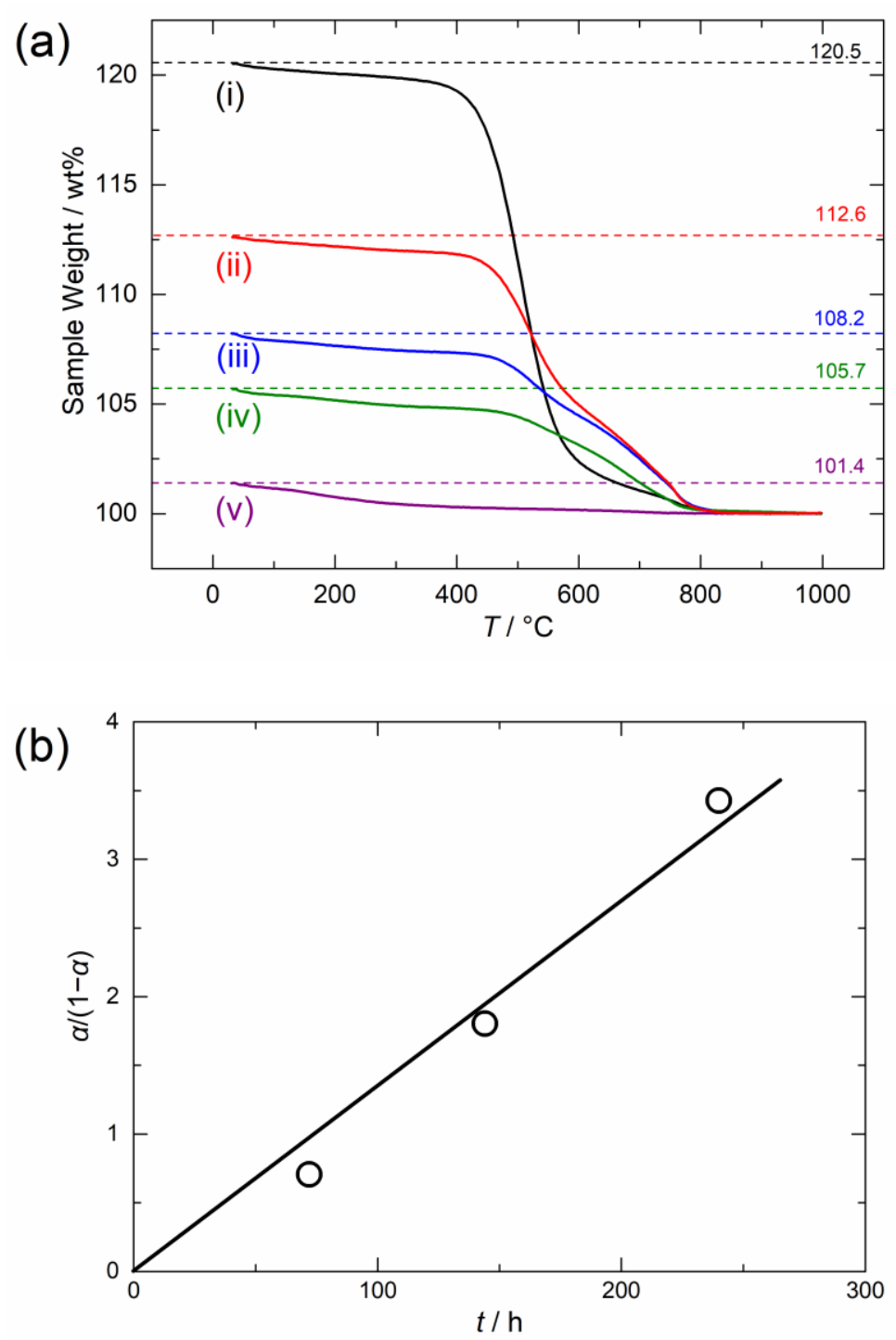

Figure 6. (a) Non-isothermal thermogravimetric (TG) curves of (i) the precursor $\left(\mathrm{Li}_{2} \mathrm{CO}_{3}\right.$ and $\mathrm{Co}_{3} \mathrm{O}_{4}$, mixture) and reaction products from $\mathrm{Li}_{2} \mathrm{CO}_{3}$ and $\mathrm{Co}_{3} \mathrm{O}_{4}$ calcined at $325{ }^{\circ} \mathrm{C}$ for (ii) 3 , (iii) 6 , and (iv) $10 \mathrm{~d}$ and (v) at $450{ }^{\circ} \mathrm{C}$ for $16 \mathrm{~h}$ (heating rate, $10{ }^{\circ} \mathrm{C} \mathrm{min}^{-1}$ ). (b) $\alpha /(1-\alpha)$ versus time $(t)$ plots for the reaction between $\mathrm{Li}_{2} \mathrm{CO}_{3}$ and $\mathrm{Co}_{3} \mathrm{O}_{4}$ at $325{ }^{\circ} \mathrm{C}$. Open circles indicate the observed $\alpha /(1-\alpha)$ of the reaction products estimated from the TG data, while the solid line indicates the $\alpha /(1-\alpha)$ values simulated from the kinetic equation (activation energy, $153 \mathrm{~kJ}$ $\mathrm{mol}^{-1}$ and frequency factor, $\left.8.6 \times 10^{7} \mathrm{~s}^{-1}\right)$. 
Analysis of the LT- to HT-LCO Phase Transition. The calcination time at which $\alpha$ reaches an arbitrary value at an arbitrary calcination temperature was estimated from the kinetic equation obtained by substituting the activation energy and pre-exponential factor determined by isothermal TG analysis into eq (5) (Figure S3). Thus, the relationship between the calcination temperature and time for $\alpha \sim 0.85$ to 0.95 , at which the reaction is considered to have proceeded sufficiently, and $\alpha=0.99$, when the reaction is almost complete, was determined. When the calcination temperature exceeded $450{ }^{\circ} \mathrm{C}$, a few hours of calcination were sufficient for the reaction to proceed sufficiently. Conversely, long calcination times (several days) were necessary to obtain a sufficient $\alpha$ value at calcination temperatures $<350{ }^{\circ} \mathrm{C}$. Therefore, the conditions for the calcination reaction were set to $325^{\circ} \mathrm{C}$ for $10 \mathrm{~d}, 350{ }^{\circ} \mathrm{C}$ for 3 $\mathrm{d}, 450{ }^{\circ} \mathrm{C}$ for $2 \mathrm{~h}$, and $500{ }^{\circ} \mathrm{C}$ for $30 \mathrm{~min}$. The XRD patterns of the samples calcined under these conditions are presented in Figure 7. Diffraction lines belonging to LCO (comprising both the LT and HT phases) were observed, while weak diffraction lines attributed to $\mathrm{Li}_{2} \mathrm{CO}_{3}$ at $2 \theta \sim 40^{\circ}$ were also present, indicating that the reaction was almost complete $(\alpha \sim 1)$.

The LT-LCO fraction in the samples was estimated by Gaussian function fitting of the maximum intensity diffraction lines so that the 111 diffraction line of LT-LCO and the 003 diffraction line of HT-LCO at $2 \theta=24^{\circ}$ were distinguished (Figure 7). ${ }^{22}$ In all the XRD patterns, the strongest diffraction line at $\sim 24^{\circ}$ could be separated into the 003 line for HT-LCO (blue) at $23.8^{\circ}$ and 111 line for LT-LCO (red) at $24.0^{\circ}$. The fraction of the LT-LCO phase was estimated by calculating the relative integrated intensity (peak area) ratio of the 111 line. The diffraction line of HT-LCO become stronger with increasing heating temperature, while that of LT-LCO became weaker. 


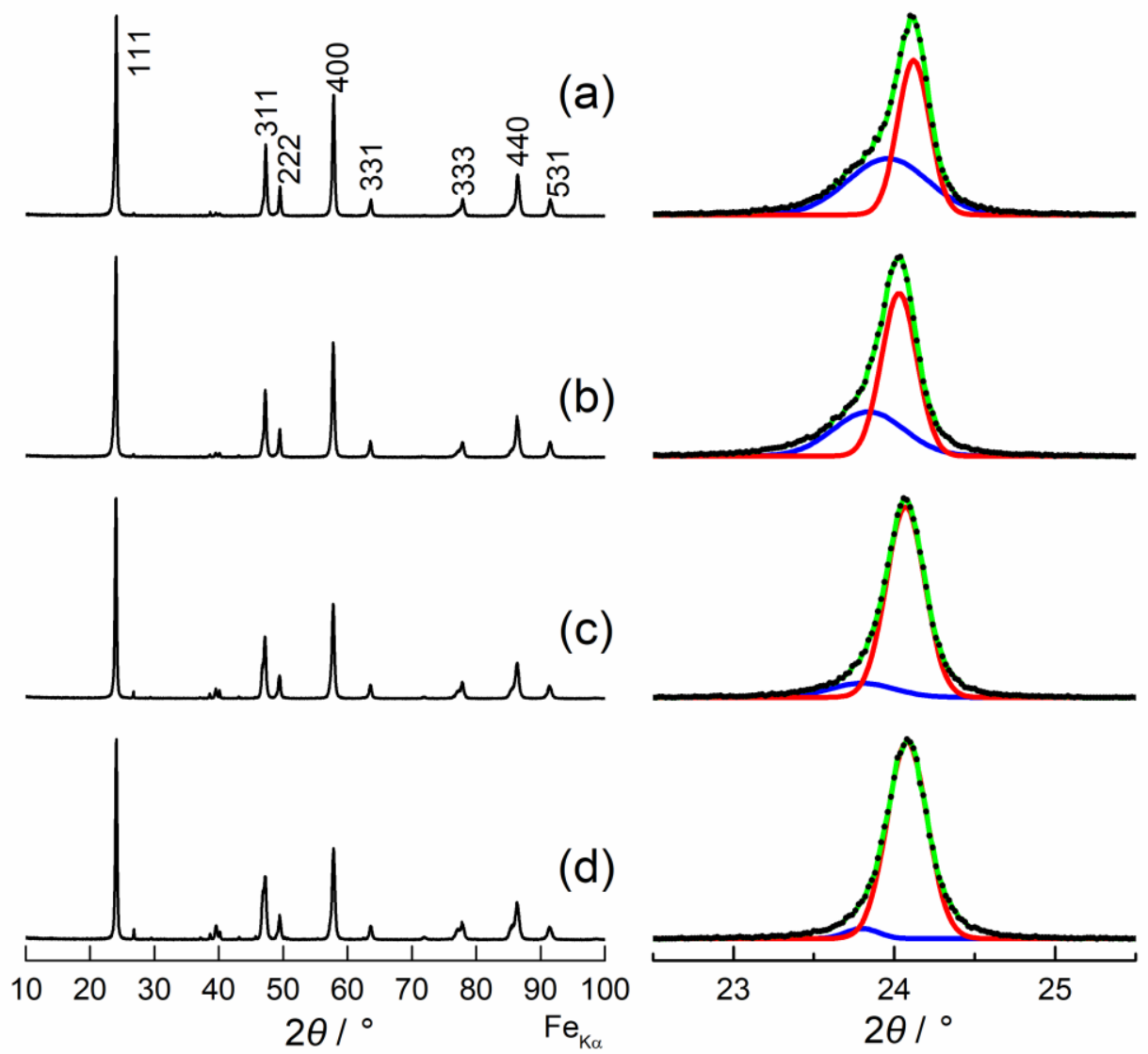

Figure 7. X-ray diffraction (XRD) patterns of the products from the calcination of $\mathrm{Li}_{2} \mathrm{CO}_{3}$ and $\mathrm{Co}_{3} \mathrm{O}_{4}$ at: (a) $500{ }^{\circ} \mathrm{C}$ for $0.5 \mathrm{~h}$, (b) $450{ }^{\circ} \mathrm{C}$ for $2 \mathrm{~h}$, (c) $350{ }^{\circ} \mathrm{C}$ for $72 \mathrm{~h}$, and (d) $325^{\circ} \mathrm{C}$ for $240 \mathrm{~h}$. The diffraction line at $24^{\circ}$ in $2 \theta$ is also displayed. Black dots indicate the observed intensities, while the solid lines are the curves fitted with the Gaussian function: 111 diffraction line for LT-LCO (red) and 003 diffraction line for HT-LCO (blue).

The fraction of the LT-LCO phase was estimated from an electrochemical viewpoint. Figure 8 shows constant current charge-discharge curves of the samples examined in a lithium cell. The discharge curve is remarkably changed and the charge curve is not significantly different. Because the polarization is larger in LT-phase than HT-phase, the charge curves are overlapped, while the difference increases in the discharge voltages. For this reason, even if the LT- and the HT-phase coexist, no difference is seen in the charge curve, while a remarkable difference is 
seen in the discharge curve. In the $\mathrm{d} Q / \mathrm{d} E$ plot shown in the Figure S5, two peaks are observed for charging, with the lower potential peak corresponding to LT and the higher peak corresponding to HT. However, it is difficult to clearly distinguish the reactions from the charge curve because of very small voltage difference in charge voltage. Because the electrochemical reaction of LT-LCO exhibits a voltage plateau at 3.5 V and that of HT-LCO displays an operating voltage $>3.9 \mathrm{~V}$, the fraction of the LT-LCO phase can be calculated from the discharge capacity $<3.6 \mathrm{~V}$. As the calcination temperature increased, the discharge capacity derived from the LT-LCO phase decreased, indicating that the sample calcined at the higher temperatures displayed lower LT-LCO fractions. To clarify the consistency of the LT-LCO fractions estimated from the XRD and electrochemical measurements, the fractions of LT-LCO estimated from the integrated intensity ratios of the 111 lines of LT-LCO were plotted against those from the discharge capacity $(<3.6 \mathrm{~V}$; Figure S4). The resultant plot revealed that the LTLCO fractions obtained from the two methods were in good agreement. 


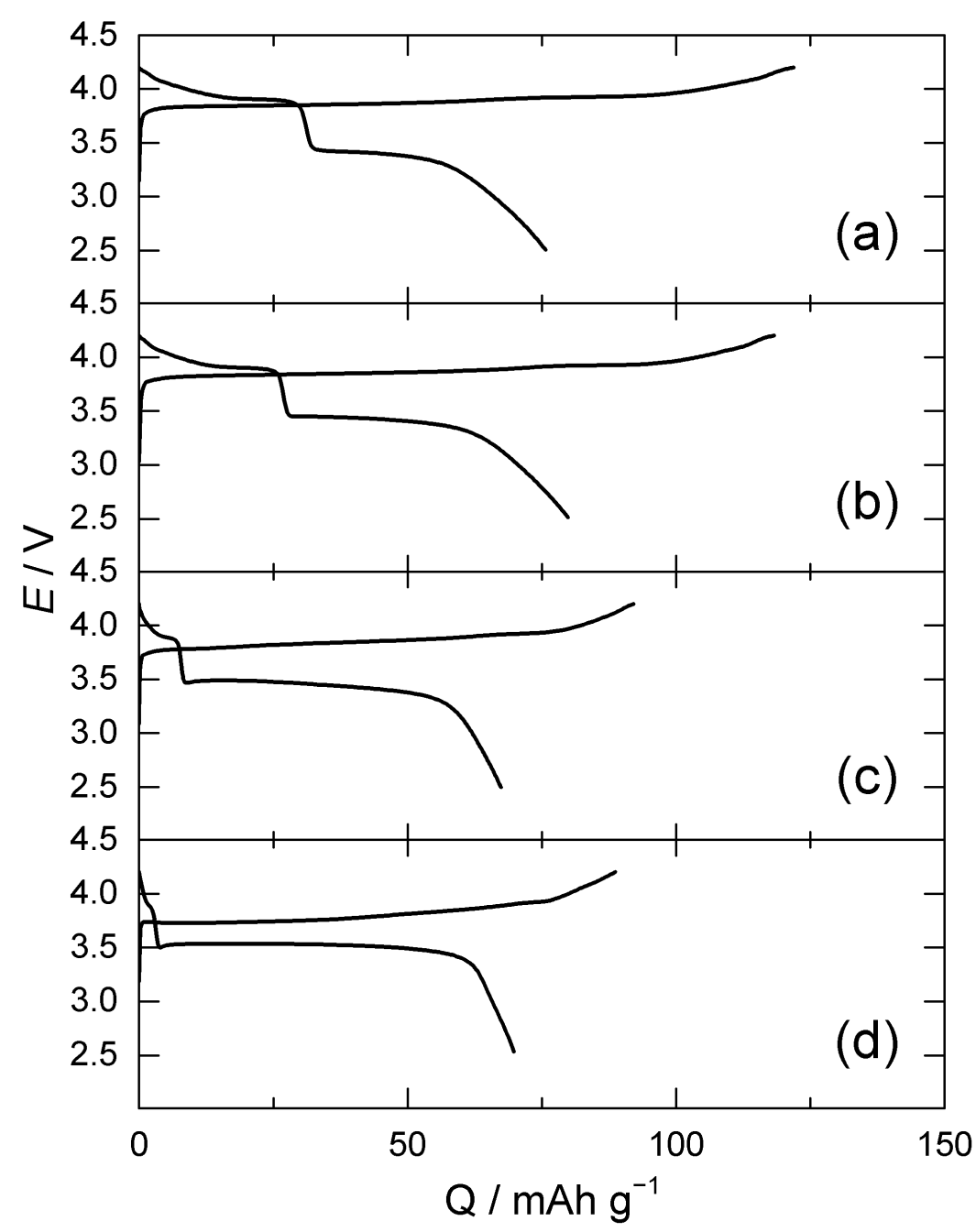

Figure 8. Charge-discharge curves of lithium cells comprising the reaction products formed from $\mathrm{Li}_{2} \mathrm{CO}_{3}$ and $\mathrm{Co}_{3} \mathrm{O}_{4}$ at (a) $500{ }^{\circ} \mathrm{C}$ for $0.5 \mathrm{~h}$, (b) $450{ }^{\circ} \mathrm{C}$ for $2 \mathrm{~h}$, (c) $350{ }^{\circ} \mathrm{C}$ for $72 \mathrm{~h}$, and (d) $325{ }^{\circ} \mathrm{C}$ for $240 \mathrm{~h}$. The cells were operated at $0.25 \mathrm{~mA} \mathrm{~cm}^{-2}$ in the voltage range $2.5-4.2 \mathrm{~V}$ at $25{ }^{\circ} \mathrm{C}$.

Figure 9 displays the LT-LCO fractions for the different calcination temperatures to clarify the relationship between the LT-LCO fraction and calcination temperature. The plot is a straight line indicating that the LT-LCO fraction decreases proportionally with increasing calcination temperature. It is possible to selectively synthesize LT-LCO at a lower temperature. ${ }^{14-17,36}$ Further, since the LT-LCO fraction reaches $100 \%$ at $300{ }^{\circ} \mathrm{C}$, the synthesis of single-phase LTLCO can be attained from calcination at temperatures $<300{ }^{\circ} \mathrm{C}$; however, the calcination time 
necessary to reach $\alpha=0.85$ by calcination at $300{ }^{\circ} \mathrm{C}$ is more than one month $(>800 \mathrm{~h}$ ).

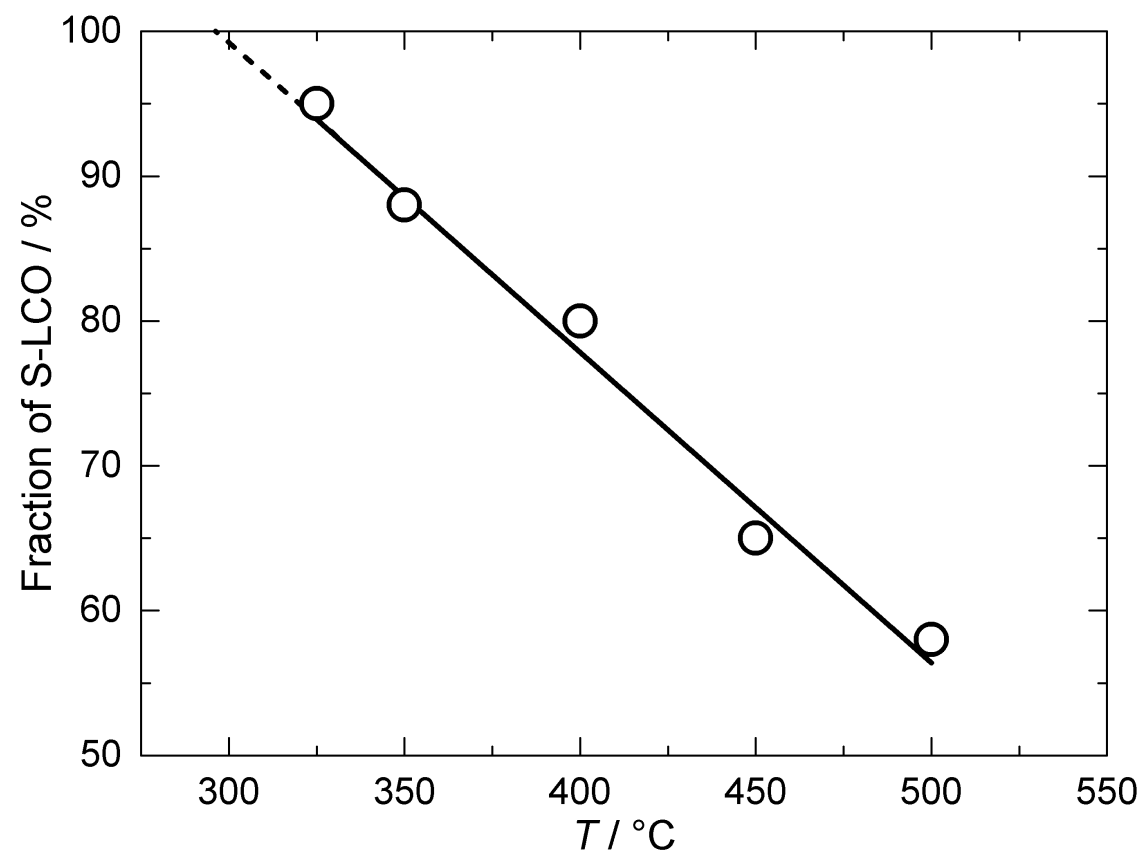

Figure 9. LT-LCO fractions in the reaction products as a function of the calcination temperatures.

To investigate the kinetics of the LT to HT phase transition, the dependence of the LT-LCO fraction on the calcination time at $450{ }^{\circ} \mathrm{C}$ (high temperature) was examined. XRD measurements (Figure S6) and charge-discharge tests (Figure S7) were therefore performed to estimate the LT-LCO fraction. Figure 10 illustrates that the LT-LCO fraction decreased with increasing calcination time, indicating that transition to the HT phase is very slow and occurs gradually with increasing calcination temperature. LT-LCO was selectively synthesized with decreasing calcination time; however, the LT-LCO fraction was $\sim 70 \%$ at its maximum, based on the hypothesis that the LT-LCO fraction was proportional to the calcination time. 


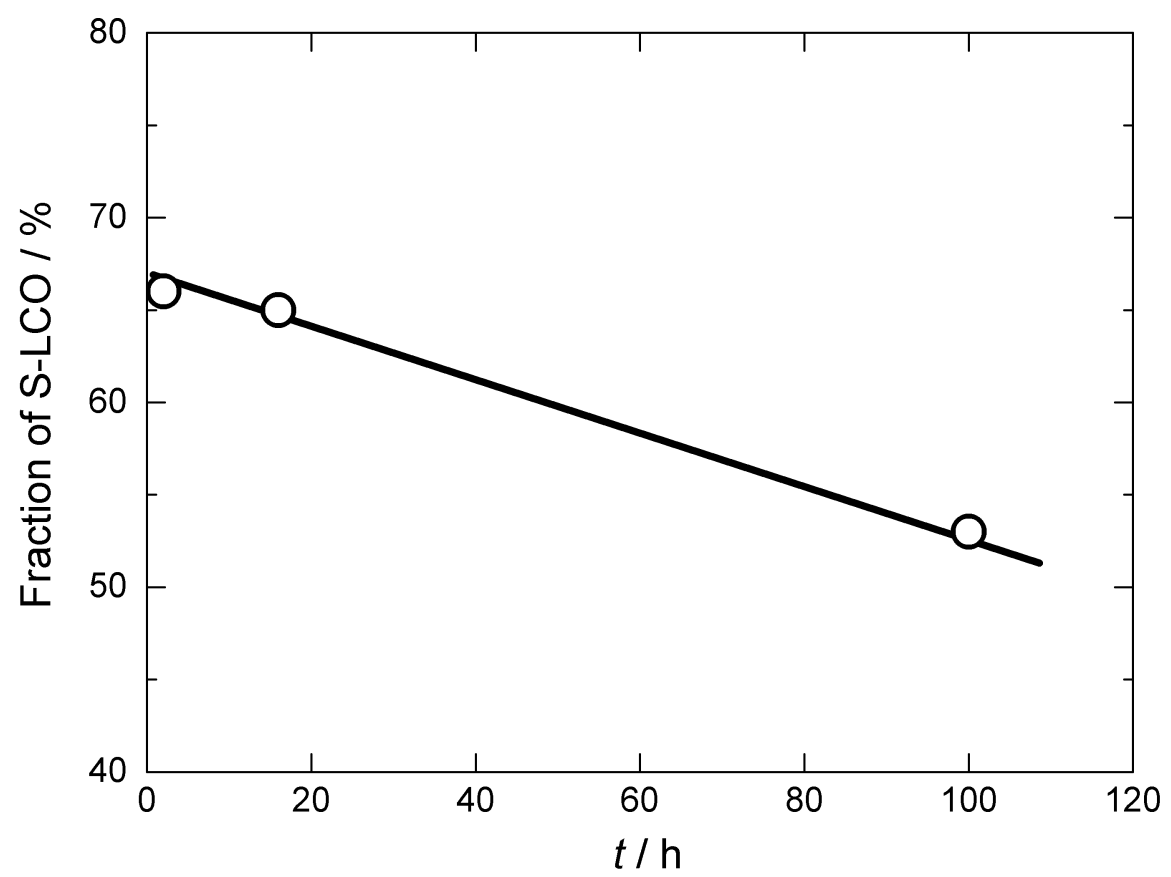

Figure 10. LT-LCO fractions in the reaction products calcined at $450{ }^{\circ} \mathrm{C}$ as a function of the calcination time.

The above results revealed the synthetic reaction mechanism of $\mathrm{LCO}$ from $\mathrm{Li}_{2} \mathrm{CO}_{3}$ and $\mathrm{Co}_{3} \mathrm{O}_{4}$ (Figure 11). The LT- and HT-LCO phases were produced simultaneously during the synthetic process. However, LT-LCO was preferably formed during low-temperature synthesis, while HT-LCO was preferentially produced from high-temperature synthesis. Hence, HT-LCO was formed by both the phase transition from LT-LCO and solid-state reaction of $\mathrm{Li}_{2} \mathrm{CO}_{3}$ and $\mathrm{Co}_{3} \mathrm{O}_{4}$, even at low temperatures. This indicated that LT-LCO synthesis mainly depends on the calcination temperature rather than the calcination time, thereby proving that low temperature synthesis $\left(<350{ }^{\circ} \mathrm{C}\right)$ is necessary to selectively prepare LT-LCO. 


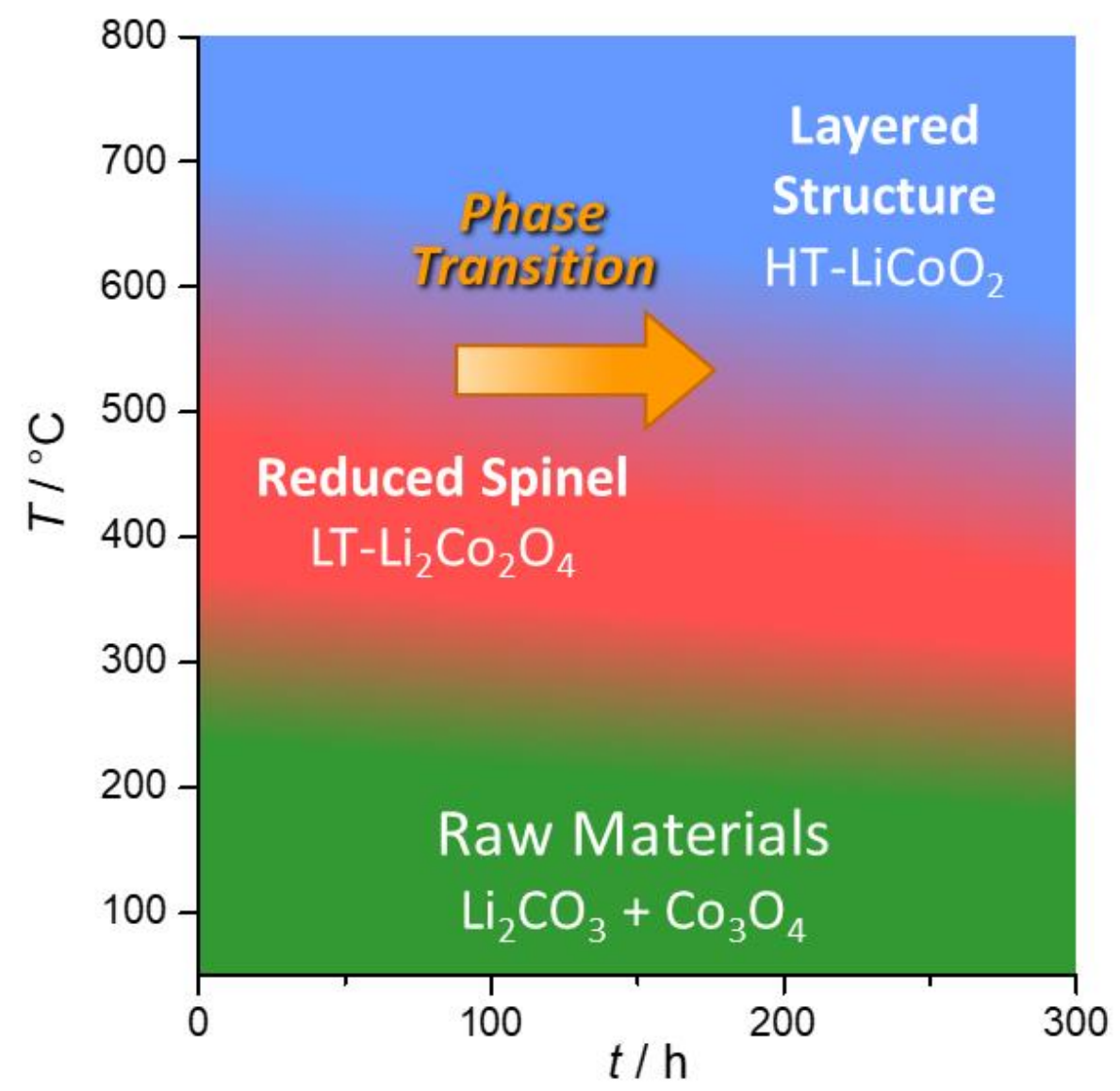

Figure 11. Diagram of the solid-state reaction of low-temperature (LT)-lithium cobalt oxide (LCO) and LT- to high-temperature (HT)-LCO phase transition.

Zero-Strain Insertion LT-LCO Material. Since the charge-discharge curve of LT-LCO is very similar to that of $\mathrm{Li}_{2} \mathrm{Ni}_{0.2} \mathrm{Co}_{1.8} \mathrm{O}_{4}$ having the same crystal structure, the reaction

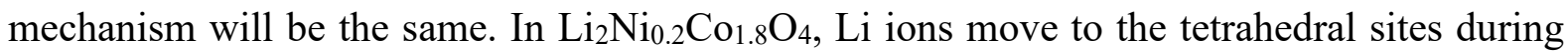
charging to form a spinel structure with quite small change in the lattice constant [19]. As well as $\mathrm{Li}_{2} \mathrm{Ni}_{0.2} \mathrm{Co}_{1.8} \mathrm{O}_{4}$, LT-LCO is expected to show negligibly small dimensional change during charging. To examine the change in the lattice dimension of LT-LCO during lithium extraction, ex-situ XRD measurements of an LCO electrode were next carried out. When the LT-LCO electrode was charged to $4.2 \mathrm{~V}$ in a lithium cell, the cell delivered the charge capacity $70 \mathrm{mAh}$ $\mathrm{g}^{-1}$ corresponding to $\sim 0.5 \mathrm{~mol} \mathrm{Li}$ extraction from $\mathrm{Li}_{2} \mathrm{Co}_{2} \mathrm{O}_{4}$. The XRD pattern of the charged 
LCO electrode was very similar to that of the powder sample: no shift in the diffraction lines, even for the lines located at higher diffraction angles that are sensitive to the change in the lattice dimension. This indicated that LT-LCO is virtually zero-strain (Figure 12a). The cubic lattice parameters of the charged and powder samples were calculated using the Nelson-Riley method ${ }^{37}$ because the precise determination of the lattice constant from Rietveld refinement is rather ambiguous. ${ }^{38}$ Figure $12 \mathrm{~b}$ illustrates that the change in the cubic lattice constant is only $0.004 \AA(8.0001 \pm 0.0005 \AA$ for the powder and $7.9955 \pm 0.0006 \AA$ for the charged samples $)$, corresponding to $0.05 \%$ of the dimensional change. Thus, by omitting Ni from the LT phase, the materials approach a zero-strain mechanism: $0.05 \%$ for LT-LCO and $0.11 \%$ for $\mathrm{Li}_{2} \mathrm{Ni}_{0.2} \mathrm{Co}_{1.8} \mathrm{O}_{4}{ }^{19}$ This change is the smallest among the lithium insertion materials of spinel structure except for LTO.
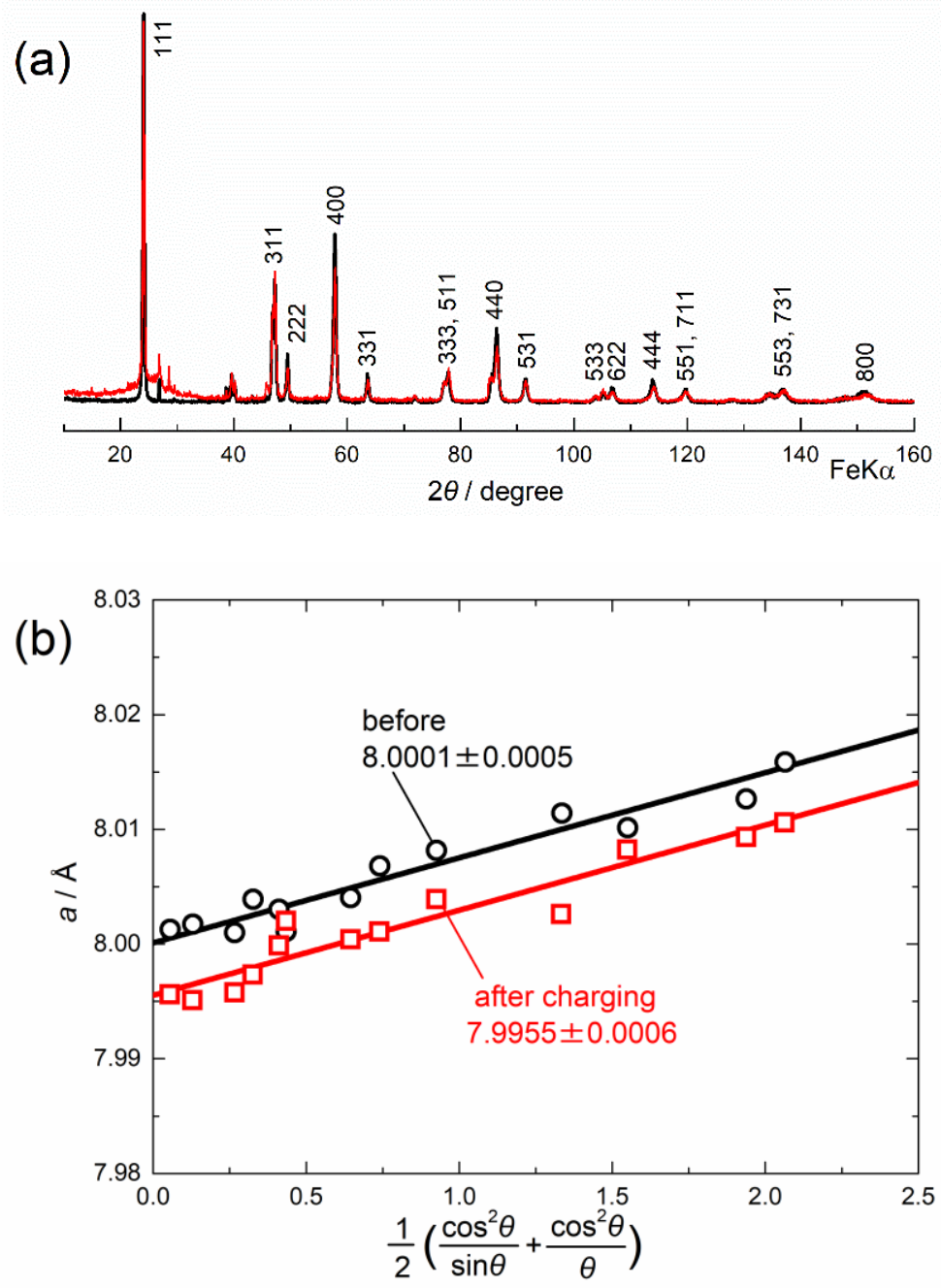
Figure 12. (a) X-ray diffraction (XRD) patterns of low-temperature (LT)-lithium cobalt oxide (LCO) before (black) and after (red) charging to $4.2 \mathrm{~V}$. (b) cubic lattice constant of LT-LCO (black) before and (red) after charging to $4.2 \mathrm{~V}$, determined from the peak position of each diffraction line versus the Nelson-Riley function.

\section{CONCLUSION}

In this study, thermal analysis was performed on the solid-state reaction between $\mathrm{Li}_{2} \mathrm{CO}_{3}$ and $\mathrm{Co}_{3} \mathrm{O}_{4}$ to determine the synthetic conditions of single-phase LT-LCO $\left(\mathrm{Li}_{2} \mathrm{Co}_{2} \mathrm{O}_{4}\right)$. Nonisothermal and isothermal TG analysis revealed that the solid-state reaction of LCO proceeds as a second-order reaction and the kinetic parameters (activation energy and pre-exponential factor) were subsequently derived. The LT-LCO fractions estimated from the integrated intensity ratio of the diffraction lines and the discharge capacity ratio indicated that the LT phase was preferentially formed at low temperatures, whereas the fraction of HT phase increased with increasing temperatures. In addition, the phase transition from LT- to HT-LCO was a very slow process. Consequently, calcination at lower temperatures and longer times was required to approach $100 \%$ LT-LCO fraction. The ex-situ X-ray diffraction measurements revealed that LT-LCO displayed zero-strain lithium insertion and that the change in the lattice dimension of the material was smaller than that of the Ni-substituted material. The results of the kinetic analysis of LT phase formation is useful for the development of novel materials of reduced spinel structure. Furthermore, the isolation of two types of LCO (HT and LT phases) having the same chemical composition and solid-phase redox species but different crystal structures is extremely useful in the study of the structural sensitivity of lithium insertion materials according to their electrochemical nature. 


\section{ASSOCIATED CONTENT}

Supporting Information. Details of the TG analysis and additional characterization of the prepared materials. This material (PDF) is available free of charge from the ACS website.

\section{AUTHOR INFORMATION}

\section{Corresponding Author}

*E-mail: ariyoshi@a-chem.eng.osaka-cu.ac.jp (K.A.); ymd@a-chem.eng.osaka-cu.ac.jp (Y.Y.).

\section{Author Contributions}

The manuscript was written through contributions of all authors. All authors have given approval to the final version of the manuscript.

\section{ACKNOWLEDGEMENT}

This work was supported by the Advanced Low Carbon Technology Research and Development Program, Specially Promoted Research for Innovative Next Generation Batteries (ALCA Spring) of the Japan Science and Technology Agency (JST) Grant Number JPMJAL1301, Japan. 


\section{REFERENCES}

(1) Whittingham, M. S. Lithium batteries and cathode materials. Chem. Rev. 2004, 104, 4271-4302.

(2) Ohzuku, T.; Brodd, R. J. An overview of positive-electrode materials for advanced lithiumion batteries. J. Power Sources 2007, 174, 449-456.

(3) Goodenough, J. B.; Kim, Y. Challenges for rechargeable Li batteries. Chem. Mater. 2009, $22,587-603$.

(4) Ellis, B. L.; Lee, K. T.; Nazar, L. F. Positive electrode materials for Li-ion and Li-batteries. Chem. Mater. 2010, 22, 691-714.

(5) Wang, J.; He, X.; Paillard, E.; Laszczynski, N.; Li, J.; Passerini, S. Lithium-and manganese-rich oxide cathode materials for high-energy lithium ion batteries. $A d v$. Energy Mat. 2016, 6, 1600906.

(6) Lin, F.; Nordlund, D.; Li, Y.; Quan, M. K.; Cheng, L. ; Weng, T.-C.; Liu, Y.; Xin, H. L.; Doeff M. M. Metal segregation in hierarchically structured cathode materials for highenergy lithium batteries. Nat. Energy 2016, 1, 15004.

(7) Ma, J.; Hu, P.; Cui, G.; Chen, L.; Surface and interface issues in spinel $\mathrm{LiNi}_{0.5} \mathrm{Mn}_{1.5} \mathrm{O}_{4}$ : insights into a potential cathode material for high energy density lithium ion batteries. Chem. Mater. 2016, 28, 3578-3606.

(8) Kim, S.; Cho, W.; Zhang, X.; Oshima, Y.; Choi, J. W. A stable lithium-rich surface structure for lithium-rich layered cathode materials. Nat. Comm. 2016, 7, 13598.

(9) Cherkashinin, G.; Sharath, S. U.; Jaegermann, W. Toward enhanced electronic and ionic conductivity in olivine $\mathrm{LiCoPO}_{4}$ thin film electrode material for $5 \mathrm{~V}$ lithium batteries: effect of $\mathrm{LiCo}_{2} \mathrm{P}_{3} \mathrm{O}_{10}$ impurity phase. Adv. Energy Mater. 2017, 7, 1602321. 
(10)Park, K.-Y.; Park, I.; Kim, H.; Yoon, G.; Gwon, H.; Cho, Y.; Yun, Y. S.; Kim, J.-J.; Lee, S.; Ahn, D.; Kim, Y.; Kim, H.; Hwang, I.; Yoong, W.-S.; Kang, K. Lithium-excess olivine electrode for lithium rechargeable batteries. Energy Environ. Sci. 2016, 9, 2902-2915.

(11) Manthiram, A. An outlook on lithium ion battery technology. ACS Cent. Sci. 2017, 3, 1063-1069.

(12) Ohzuku, T.; Ueda, A. Solid-state redox reactions of $\mathrm{LiCoO}_{2}(\mathrm{R} 3 \mathrm{~m})$ for 4 volt secondary lithium cells. J. Electrochem. Soc. 1994, 141, 2972-2977.

(13)Chen, Z.; Dahn, J. R. Methods to obtain excellent capacity retention in $\mathrm{LiCoO}_{2}$ cycled to 4.5 V. Electrochim. Acta 2004, 49, 1079-1090.

(14) Antolini, E. $\mathrm{LiCoO}_{2}$ : Formation, structure, lithium and oxygen nonstoichiometry, electrochemical behavior and transport properties. Solid State Ionics 2004, 170, 159-171.

(15) Rossen, E.; Reimers, J. N.; Dahn, J. R. Synthesis and electrochemistry of spinel LT-LiCoO2. Solid State Ionics, 1993, 62, 53-60.

(16) Shao-Horn, Y.; Hackney, S. A.; Johnson, C. S.; Kahaian, A. J.; Thackeray, M. M. Structural features of low-temperature $\mathrm{LiCoO}_{2}$ and acid-delithiated products. J. Solid State Chem. 1998, 140, 116-127.

(17) Shao-Horn, Y.; Hackney, S. A.; Kahaian, A. J.; Thackeray, M. M. Structural stability of $\mathrm{LiCoO}_{2}$ at $400^{\circ}$ C. J. Solid State Chem. 2002, 168, 60-68.

(18)Lee, E.; Blauwkamp, J.; Castro, F. C.; Wu, J.; Dravid, V. P.; Yan, P.; Wang, C.; Kim, S.; Wolverton, C.; Benedek, R.; Dogan, F.; Park, J. S.; Croy, J. R.; Thackeray, M. M. Exploring lithium-cobalt-nickel oxide spinel electrodes for $\geq 3.5 \mathrm{~V}$ Li-ion cells. ACS Appl. Mater. Interfaces 2016, 8, 27720-27729.

(19) Ariyoshi, K.; Orikasa, Y.; Kajikawa, K.; Yamada, Y. $\mathrm{Li}_{2} \mathrm{Ni}_{0.2} \mathrm{Co}_{1.8} \mathrm{O}_{4}$ having a spinel framework as a zero-strain positive electrode material for lithium-ion batteries. J. Mater. Chem. A 2019, 7, 13641-13649. 
(20)Choi, S.; Manthiram, A. Synthesis and electrochemical properties of $\mathrm{LiCo}_{2} \mathrm{O}_{4}$ spinel cathodes. J. Electrochem. Soc. 2002, 149, A162-A166.

(21)Choi, S.; Manthiram, A. Chemical synthesis and properties of spinel $\mathrm{Li}_{1-\mathrm{x}} \mathrm{Co}_{2} \mathrm{O}_{4-\delta}$. J. Solid State Chem. 2002, 164, 332-338.

(22)Kan, Y.; Hu, Y.; Ren, Y.; Bareño, J.; Bloom, I.; Sun, Y. K.; Amine, K.; Chen, Z. Differentiating allotropic $\mathrm{LiCoO}_{2} / \mathrm{Li}_{2} \mathrm{Co}_{2} \mathrm{O}_{4}$ : A structural and electrochemical study. $J$. Power Sources 2014, 271, 97-103.

(23) Ohzuku, T.; Ueda, A.; Yamamoto, N. Zero-strain insertion material of $\mathrm{Li}\left[\mathrm{Li}_{1 / 3} \mathrm{Ti}_{5 / 3}\right] \mathrm{O}_{4}$ for rechargeable lithium cells. J. Electrochem. Soc. 1995, 142, 1431-1435.

(24) Ariyoshi, K.; Yamato, R.; Ohzuku, T.; Zero-strain insertion mechanism of Li[ $\left.\mathrm{Li}_{1 / 3} \mathrm{Ti}_{5 / 3}\right] \mathrm{O}_{4}$ for advanced lithium-ion (shuttlecock) batteries. Electrochim. Acta 2005, 51, 1125-1129.

(25) Ariyoshi, K.; Yamamoto, H.; Yamada, Y. Relationship between changes in ionic radius and lattice dimension of lithium manganese oxide spinels during lithium insertion/extraction. Solid State Ionics, 2019, 343, 115077.

(26) Ariyoshi, K.; Yamamoto, H.; Yamada, Y. High dimensional stability of $\mathrm{LiCoMnO}_{4}$ as positive electrodes operating at high voltage for lithium-ion batteries with a long cycle life. Electrochim. Acta, 2018, 260, 498-503.

(27) Young, R. A. The Rietveld Method, Young, R. A. ed.; Oxford Univ. Press, Oxford, 1993, Chap. 1.

(28) Ozawa, T. A New Method of analyzing thermogravimetric data. Bull. Chem. Soc. Jpn. 1965, $38,1881-1886$.

(29)Kissinger, H. E. Reaction kinetics in differential thermal analysis. Anal. Chem. 1957, 29, $1702-1706$.

(30)Khawam, A.; Flanagan, D. R. Solid-state kinetic models: Basics and mathematical fundamentals. J. Phys. Chem. B 2006, 110, 17315-17328. 
(31) Vyazovkin, S.; Burnham, A. K.; Criado, J. M.; Perez-Maqueda, L. A.; Popescu, C.; Sbirrazzuoli, N. ICTAC kinetics committee recommendations for performing kinetic computations on thermal analysis data. Thermochim. Acta 2011, 520, 1-19.

(32)Lin, S. P.; Fung, K. Z.; Hon, Y. M.; Hon, M. H. Crystallization kinetics and mechanism of the $\mathrm{Li}_{\mathrm{x}} \mathrm{Ni}_{2-\mathrm{x}} \mathrm{O}_{2}(0 \leq \mathrm{x} \leq 1)$ from $\mathrm{Li}_{2} \mathrm{CO}_{3}$ and $\mathrm{NiO}$. J. Cryst. Growth 2002, 234, 176-183.

(33) Lu, C. H.; Wei-Cheng, L. Reaction mechanism and kinetics analysis of lithium nickel oxide during solid-state reaction. J. Mater. Chem. 2000, 10, 1403-1407.

(34)Lu, C. H.; Yeh, P. Y.; Hsu, W. T. Non-isothermal reaction kinetics of lithium cobalt oxide. J. Alloys Compd. 2009, 476, 749-754.

(35) Vyazovkin, S.; Chrissaafis, K.; Di Lorenzo, M. L.; Koga, N.; Pijolat, M.; Roduit, B.; Sbirrazzuoli, N.; Snol, J. J. ICTAC kinetics committee recommendations for collecting experimental thermal analysis data for kinetic computations. Thermochim. Acta 2014, 590, $1-23$.

(36) Porthault, H.; Baddour-Hadjean, R.; Le Cras, F.; Bourbon, C.; Franger, S. Raman study of the spinel-to-layered phase transformation in sol-gel $\mathrm{LiCoO}_{2}$ cathode powders as a function of the post-annealing temperature. Vib. Spectrosc., 2012, 62, 152-158.

(37) Nelson, J. B.; Riley, D. P. An experimental investigation of extrapolation methods in the derivation of accurate unit-cell dimensions of crystals. Proc. Phys. Soc. 1945, 57, 160.

(38) Tsubota, M.; Kitagawa, J. A necessary criterion for obtaining accurate lattice parameters by Rietveld method. Sci. Rep. 2017, 7, 15381. 